\title{
Protein NOV Homolog
}

National Cancer Institute

\section{Source}

National Cancer Institute. Protein NOV Homolog. NCI Thesaurus. Code C18575.

Protein NOV homolog (357 aa, $39 \mathrm{kDa}$ ) is encoded by the human NOV gene. This protein is involved in the regulation of cell growth. 